\title{
The Impact of Cooperative Learning on EFL Achievers' and Underachievers' Motivation Based on Marginal Utility
}

\author{
Xueqing $\mathrm{Wu}$ \\ School of Foreign Languages, Hunan University, Changsha, Hunan Province, 410082, China \\ Mingxing Tao \\ School of Foreign Languages, Hunan University, Changsha, Hunan Province, 410082, China
}

\begin{abstract}
This study explores the change of EFL learners' motivation in learning English with the increase of CL time based on marginal utility. Thirty learners from an intact class in Grade 10 were selected through their performance on a piloted sample Preliminary English Test. Learners were assigned to achievers and underachievers groups. The questionnaire of motivation, based on the Attitude/Motivation Test Battery (AMTB), was given to both groups as a pretest. All participants underwent the same amount of teaching time and same material with the same teacher during seven-week CL, 35 sessions taking 45 minutes each. The same questionnaire was administered again at the end of one week, three-week, five-week and seven-week treatments respectively to both groups and their scores on the questionnaires were compared through an analysis of Paired Samples t-test and ANOVA. The findings showed that after one week CL, both the achievers' and underachievers' motivations were significantly improved compared with those in pretest; after three-week $C L$, the underachievers' intrinsic and extrinsic motivations and achievers' extrinsic motivation declined significantly compared with those of Week One, while the latter's intrinsic motivation has no significant change; after five-week $C L$, underachievers' motivation didn't change significantly compared with their motivation in the pretest, which means that the marginal utility took place in underachievers' motivation during three-week to five-week CL; after seven-week CL, the achievers' motivation increased significantly compared with their motivation in the pretest, indicating there was no marginal utility for achievers' motivation during seven-week $\mathrm{CL}$.
\end{abstract}

Index Terms - cooperative learning, learning motivation, EFL achievers, EFL underachievers, marginal utility

\section{INTRODUCTION}

Among numerous factors exerting influence on SLA, motivation has often been viewed as the most significant one (Dornyei, 2001; Hiromori, 2006; MacIntyre, Gardner, 1989; Shamiry, R.\&Fuad, 2020; Jr, R. R.\&Nunez, A. M. ,2020). Gardener (1985) proposes that motivation is a necessary factor in language learning and language learners' academic achievements are related closely to their motivations. From the perspective of Self-determination theory, there are two kinds of motivations: intrinsic motivation and extrinsic motivation. Extrinsic motivation is the desire or tendency toward getting some external reward or avoiding punishment while intrinsic motivation is to carry out an activity for its own sake, for getting pleasure and satisfaction in doing it (Deci, Ryan, 1985, 1991; Ryan, Deci, 2000). Cooperative learning (CL), a learning strategy in which students cooperate for common goals (Roger \& Johnson, 1994; Siegel, 2005; Slavin, 1983), has been proved to make students more actively involved in learning activities compared with traditional teaching methods (Xiao, 2001; Wang, 2001; Tran, 2019; Wang, 2020; et al.). CL has been a widespread learning model in China and more and more English teachers adopt it in classroom teaching. However, many surveys proved that Chinese EFL learners, especially English underachievers, still lack strong learning motivation in CL (Dong,2018; Yao, 2013; Lu, 2009), which may result from the effect of marginal utility of CL. However, less is known about the effect of marginal utility on EFL learners' motivation in CL. Therefore, this study attempts to explore the change of EFL learners' motivation in learning English with the increase of CL time based on marginal utility.

\section{THEORETICAL FRAMEWORK}

This paper adopts marginal utility as its theoretical foundation.

In economics, utility is the satisfaction or benefit derived by consuming a product; thus the marginal utility of a good or service describes how much pleasure or happiness is gained from an increase in consumption. It may be positive, negative, or zero. In the context of cardinal utility, economists postulate a law of diminishing marginal utility, which describes how the first unit of consumption of a particular good or service yields more utility than the second and subsequent units, with a continuing reduction for greater amounts. (Investopedia. Retrieved, 2021-08-31). 
Polleit and Thorsten (2011) believe that the more you get, the less you want. For example, three bites of bread are better than two bites, but the thirtieth bite does not add much to the experience beyond the twenty-ninth (and could even make it worse).

The effect of marginal utility also exists in education (Jiang, 1999; Bai, 2009; Gui, et al., 2012). Students always have high learning motivation when they begin to acquire new knowledge. However, high learning motivation cannot last for a long time because they would feel dissatisfied or bored with the increase of learning content. This phenomenon is regarded as the effect of marginal utility in teaching.

According to marginal utility, Gui Maozhong et al. (2012) describes the effect of marginal utility in the following figure.

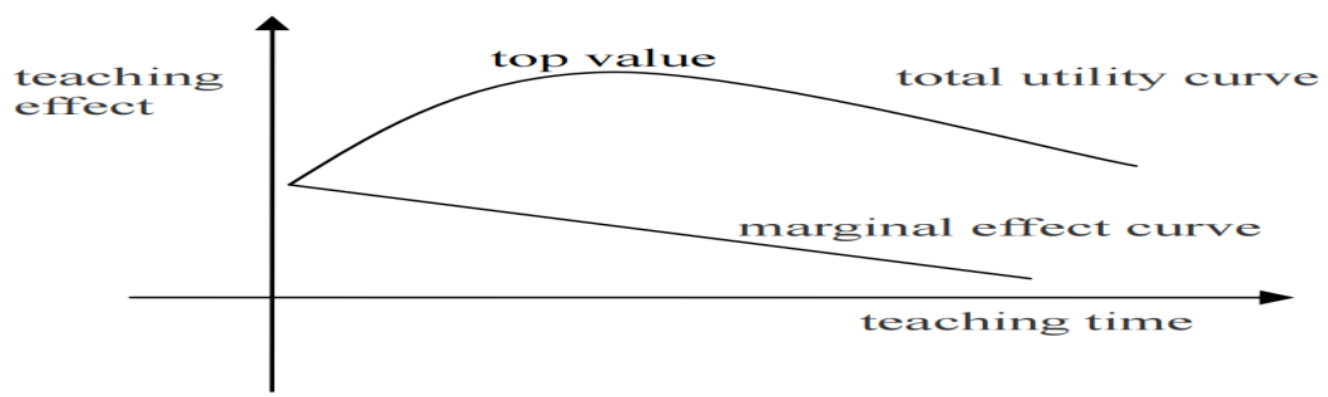

Figure 1. The Effect of Marginal Utility in Teaching (Gui Maozhong et al., 2012)

Figure1 means that if you add a class, the total utility of the classroom teaching will be enhanced. At this time, the highest marginal utility of classroom teaching is obtained. If you continue to increase the classroom hours, the total utility will continue to enhance. However, the marginal utility of classroom teaching began to decline if we continue to increase the classroom hours.

\section{Previous Studies On Motivation In CoOPerative LeARning}

Piaget (1980) regarded motivation as a built-in unconscious striving towards more complex and differential development of an individual's mental structure. Gardener (1985) pointed out that motivation, as a crucial factor in language learning, was closely associated with students' academic achievements and he thinks effort and desire are prerequisites for motivation. Dörnyei (1998) proposed that motivation can make a student start learning a foreign language and sustain the effort throughout the long learning process in second language acquisition. Based on Self-determination theory, motivation can be divided into two kinds: intrinsic motivation and extrinsic motivation. Intrinsic motivation involves carrying out a task because of pleasure and satisfaction. EFL intrinsic motivation refers to the enjoyment of learning English for its own sake rather than because of external rewards. Extrinsic motivation involves integrated regulation, which is mainly linked to a desire to be involved in the target community and to identify with its members (Noels et al., 2000). EFL extrinsic motivation means learning English for its outcomes, such as passing exams (Noels, 2001; Noels, Clement \& Pelletier, 2001).

CL is a learning model in which students work together in order to achieve common goals (Roger \& Johnson, 1994; Siegel, 2005; Slavin, 1983). Motivational perspectives on CL focus on three elements: goal structures, reward structures, and group dynamics (Dörnyei 1997; Johnson, 1991; Slavin 1997). Goal structures offer a situation where students would help each other because of a common goal. Reward structures mean that students'performance would be assessed based on whole group performance and group dynamics are closely linked to positive interdependence, individual accountability and strong group cohesiveness. According to the previous research, these elements have positive effects on students' motivation, which means CL can make students more actively involved in learning activities compared with traditional teaching methods (Davidson, 2020; Kate Ferguson-Patrick \& Wendy Jolliffe, 2018; Gülüzar Eymur \& Ömer Geban,2017). However, many surveys proved that Chinese EFL learners lack strong learning motivation, especially English underachievers (Dong, 2018; Yao, 2013; Lu, 2009). Several studies explained this phenomenon from the perspective of marginal utility.

Jiang (1999) discussed the diminishing marginal utility in students' learning behavior. He holds that there is diminishing marginal utility for students in the process of acquiring knowledge, getting criticism and praise from teachers. Bai (2009), who studied fossilization from the perspective of the law of diminishing marginal utility, pointed out that the extrinsic motivation of most Chinese EFL learners was driven by examinations. Without test pressure, some students would even give up language learning. Zhang (2011) applied marginal utility to English vocabulary teaching. She suggested that teachers timely adjust teaching methods and apply a reasonable evaluation system to carry out vocabulary teaching based on students' different learning styles. Although these scholars have noticed the effect of marginal utility in teaching management, less is known about the effect of marginal utility on EFL learners' motivation in $\mathrm{CL}(\mathrm{Wu}, 2021)$. 


\section{RESEARCH QuESTIONS}

Although the gap between the EFL achievers and underachievers is not caused by a single factor, learning motivation is considered as a crucial factor affecting students' learning achievements (Schunk, D., H \& Pintrich, P, R. 1995; Zhang Xiaoling, 2017). In this study, the researcher wants to explore the differences of changes in learning motivation of English achievers and underachievers in different CL time duration. Thus the research questions of this study are as follows:

1: What is the effect of CL on EFL achievers' motivation with the increase of CL time?

2: What is the effect of CL on EFL underachievers' motivation with the increase of CL time?

3: What are the differences of changes between achievers' and underachievers' motivation with the increase of CL time?

\section{Methodology}

\section{A. Participants}

All the sixty students from one intact class in Grade 10 in Linxiang District No.1 Middle School participated in the Preliminary English Test. Then, according to their scores on the test, thirty students were selected as participants, including fifteen English achievers (top 25 percent) and fifteen underachievers (bottom 25 percent). There is a significant difference between achievers' and underachievers' test scores. These participants are aged between sixteen to seventeen, including 13 females (six in the achievers group) and 17 males (nine in the achievers group).

\section{B. Instruments}

On the basis of qualitative and quantitative research methods, the results are analyzed through SPSS 25.0. There are two instruments adopted in this experiment: questionnaire and interview.

\section{Questionnaire}

Most items are from The Attitude/Motivation Test Battery (AMTB) developed by Gardner (1985) and the author divided the items of the questionnaire into two parts, intrinsic motivation and extrinsic motivation. Because this questionnaire will be reused many times, the order of items was rearranged to avoid practice effect. A standard five-point Likert scale was used in the questionnaire, ranging from one to five (respectively representing "strong disagreement" to "strong conformity") for scoring.

The validity and reliability of the questionnaire were tested in the pilot study. The results are as follows:

TABLE 1

THE RELIABILITY OF QUESTIONNAIRE

\begin{tabular}{lll} 
& THE RELIABILITY OF QUESTIONNAIRE & Cronbach's Alpha \\
The Whole Questionnaire & $\mathrm{N}$ & O.928 \\
Intrinsic motivation & 20 & 0.942 \\
Extrinsic motivation & 10 & 0.828 \\
\hline
\end{tabular}

The reliability coefficients of intrinsic motivation and extrinsic motivation are 0.942 and 0.828 respectively, and the reliability coefficient of the whole questionnaire is 0.928 .

TABLE 2

THE VALIDITY OF QUESTIONNAIRES

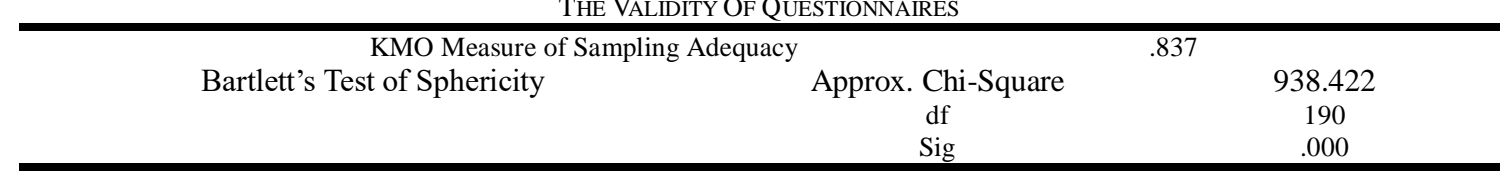

The KMO is 0.837 and $\mathrm{P}$ value is $0.000(<0.05)$.

\section{Interview}

The purpose of the interview is to explore in-depth reasons why the interviewees' motivation changes. Considering students' limited English proficiency, all interviewees and interviewer speak Chinese in order to understand each other better. The open-ended interview consists of two questions:

1 Do you like Cooperative learning activities? Why?

2 What do you think are the advantages and disadvantages of cooperative learning?

\section{Procedure}

This study started on September 10, 2020, and lasted for seven weeks. Before the study, the researcher did a pilot study to select participants and check whether all participants could fully understand the items of this questionnaire. At the beginning of the first week, the researcher distributed questionnaire in the whole class so as to get the data of their initial motivation (only achievers and underachievers' responded questionnaires were analyzed).

The teacher divides sixty students into ten groups equally with careful consideration given to heterogeneity within a team and homogeneity between teams. These home teams are fixed for the whole semester and they have one group 
leader who takes responsibility to organize class discussions and activities. Each group has its own special group name and each member has his own code-name.

In order to stimulate students to engage in group activities actively, and avoid students hitchhiking, the CL techniques, Student-Team-Achievement-Division (STAD) and Numbered-Heads-Together (NHT) were used in class. After the teacher assigns tasks to each group, the team members will work together in a limited time and the teacher is able to provide scaffolding when necessary. Usually, the teacher will randomly select one group to prepare a class presentation and one student with a specific code number would be chosen arbitrarily to do a presentation as a representative of his or her group once a week.

Students' performance is evaluated by peers and teachers through giving scores and feedback. Each student answers one question actively in class, winning one point for his or her home group. In the middle and end of the semester, teachers will select the best group based on their performance in class and test scores.

The same questionnaires with changed orders of items were distributed at the end of week one, week three, week five, and week seven respectively. At the end of the third week, the researcher interviewed all research participants one by one.

Finally, the data on motivation were collected from the questionnaire and analyzed by SPSS 25.0.

\section{Results}

\section{Questionnaire}

According to the data from the questionnaire, the following chart of participants' motivation (extrinsic motivation and intrinsic motivation) was drawn.

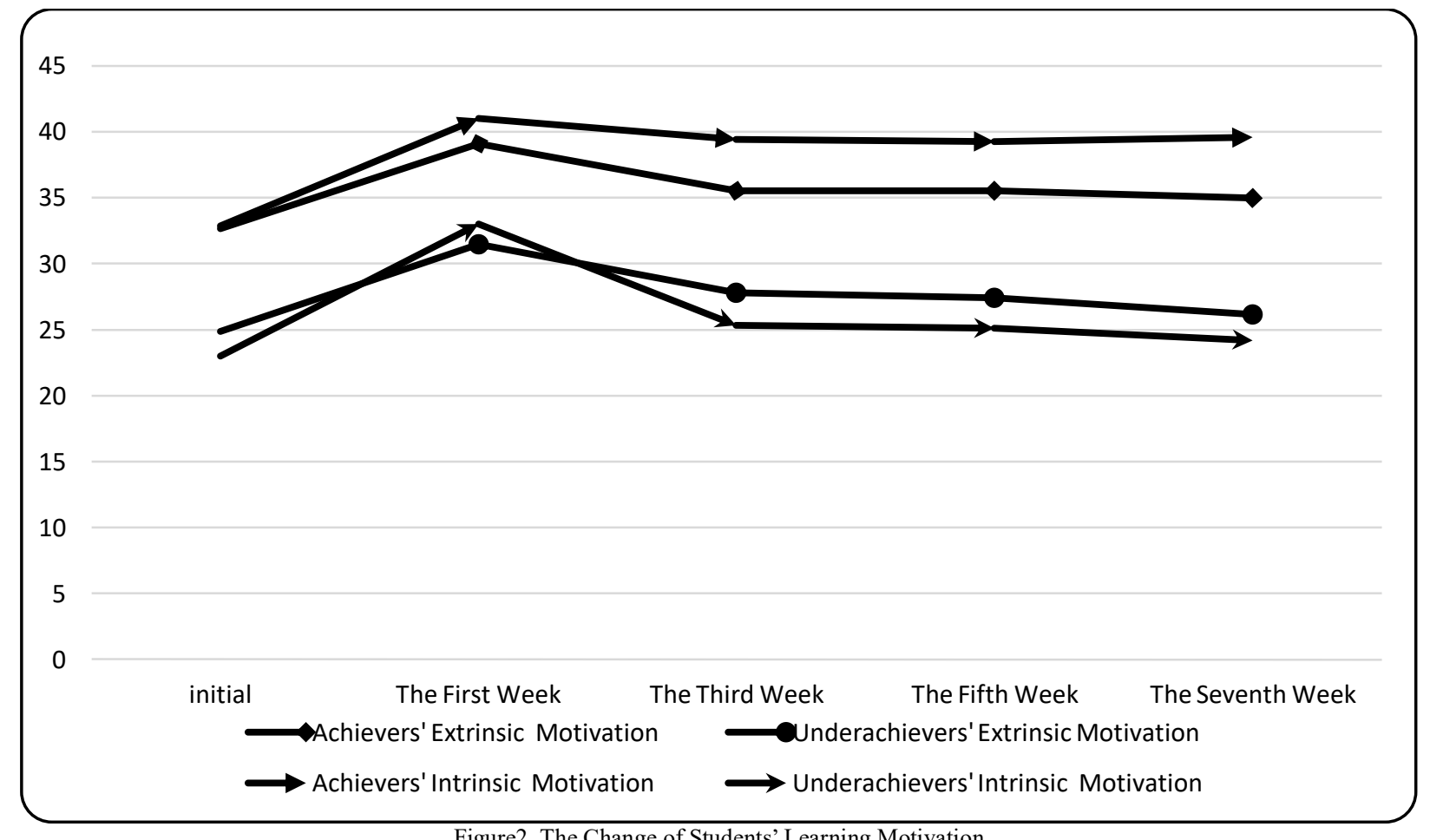

Figure2. The Change of Students' Learning Motivation

Because all scores enjoyed normalcy of distribution, ANOVA and paired samples t-test were used to test whether there is a significant difference between different CL time duration. 
TABLE 3

TESTS OF WITHIN-SUBJECTS CONTRASTS (ACHIEVERS' MOTIVATION)

\begin{tabular}{|c|c|c|c|c|c|c|}
\hline \multicolumn{7}{|c|}{ Measure: $\quad$ MEASURE_1 } \\
\hline Source & $\mathrm{M}$ & $\begin{array}{l}\text { Type III Sum } \\
\text { of Squares }\end{array}$ & df & Mean Square & $\mathrm{F}$ & Sig. \\
\hline \multirow[t]{8}{*}{ Mo } & & 614.400 & 1 & 614.400 & 55.280 & .000 \\
\hline & Initial vs. The First Week & $992.267 *$ & $1 *$ & $992.267 *$ & $42.911 *$ & $.000 *$ \\
\hline & & 187.267 & 1 & 187.267 & 11.718 & .004 \\
\hline & The First Week vs. The Third Week & $38.400^{*}$ & $1 *$ & $38.400 *$ & $2.301 *$ & $.152 *$ \\
\hline & & .000 & 1 & .000 & .000 & 1.000 \\
\hline & The Third Week vs. The Fifth Week & $.267^{*}$ & $1 *$ & $.267 *$ & $.043 *$ & $.840^{*}$ \\
\hline & & 4.267 & 1 & 4.267 & .416 & .530 \\
\hline & The Fifth Week vs. The Seventh Week & $1.667 *$ & $1 *$ & $1.667 *$ & $.700 *$ & $.417 *$ \\
\hline
\end{tabular}

Without "*” meaning extrinsic motivation, "*” indicating intrinsic motivation.

Table3 shows that after one week of CL, the EFL achievers' L2 motivation (intrinsic motivation and extrinsic motivation) increased significantly ( $<<0.05)$; after three weeks of $C L$, their extrinsic motivation decreased significantly, but there is no significant difference of intrinsic learning motivation $(\mathrm{P}>0.05)$; after five weeks of $\mathrm{CL}$, there is no significant difference of the achievers' motivation between three-week CL and five-week CL.

TABLE 4

TESTS OF WITHIN-SUBJECTS CONTRASTS (UNDERACHIEVERS' MOTIVATION)

\begin{tabular}{|c|c|c|c|c|c|c|}
\hline \multicolumn{7}{|l|}{ Measure: } \\
\hline Source & M & $\begin{array}{l}\text { Type III Su } \\
\text { Squares }\end{array}$ & df & Mean Square & $\mathrm{F}$ & Sig. \\
\hline \multirow[t]{8}{*}{ Мо } & \multirow{3}{*}{ Initial vs. The First Week } & 653.400 & 1 & 653.400 & 19.563 & .001 \\
\hline & & $1500.000 *$ & $1 *$ & $1500.000 *$ & $11.551 *$ & $.004 *$ \\
\hline & & 201.667 & 1 & 201.667 & 6.546 & .023 \\
\hline & \multirow[t]{2}{*}{ The First Week vs. The Third Week } & $881.667 *$ & $1^{*}$ & $881.667^{*}$ & $8.124^{*}$ & $.013^{*}$ \\
\hline & & 2.400 & 1 & 2.400 & .071 & .793 \\
\hline & \multirow[t]{2}{*}{ The Third Week vs. The Fifth Week } & $.600 *$ & $1^{*}$ & $.600^{*}$ & $.006^{*}$ & $0.941 *$ \\
\hline & & 24.067 & 1 & 24.067 & .439 & .518 \\
\hline & The Fifth Week vs. The Seventh Week & $13.067 *$ & $1 *$ & $13.067 *$ & $.128 *$ & $.726^{*}$ \\
\hline
\end{tabular}

Without "*" meaning extrinsic motivation, "*” signifying intrinsic motivation.

Table4 shows that after one week of CL, the EFL underachievers' motivation increased significantly $(\mathrm{P}<0.05)$; after three weeks of CL, the underachievers' motivation decreased significantly; after five weeks of CL, there is no significant difference of the underachievers' motivation between three-week CL and five-week CL (P > 0.05).

TABLE 5

PAIRED-SAMPles T TEST OF L2 LEARNING MOTIVATION

\begin{tabular}{|c|c|c|c|c|c|c|c|c|c|}
\hline & & Mean & $\begin{array}{l}\text { Std. } \\
\text { Deviation }\end{array}$ & $\begin{array}{l}\text { Std. } \\
\text { Mean }\end{array}$ & Lower & Upper & $\mathrm{t}$ & df & Sig(2-tailed) \\
\hline \multirow{4}{*}{ The Seventh Week-Initial } & 1 & -2.333 & 3.754 & .969 & -4.412 & -.254 & -2.407 & 14 & .030 \\
\hline & 2 & -1.267 & 3.515 & .907 & -3.213 & .680 & -1.396 & 14 & .185 \\
\hline & 3 & -6.733 & 3.305 & .853 & -8.564 & -4.903 & -7.890 & 14 & .000 \\
\hline & 4 & -1.200 & 3.098 & .800 & -2.916 & .516 & -1.500 & 14 & .156 \\
\hline
\end{tabular}

1 refers to achievers' extrinsic motivation; 2 refers to underachievers' extrinsic motivation; 3 refers to achievers' intrinsic motivation; 4 refers to underachievers' intrinsic motivation.

After seven-week CL, the EFL achievers' motivation has been improved significantly, but that of the underachievers was not.

TABLE 6

PAIRED-SAMPLES T TEST OF L2 LEARNING MOTIVATION (UNDERACHIEVERS)

\begin{tabular}{|c|c|c|c|c|c|c|c|c|c|}
\hline & & Mean & $\begin{array}{l}\text { Std. } \\
\text { Deviation }\end{array}$ & $\begin{array}{l}\text { Std. } \\
\text { Mean }\end{array}$ & Lower & Upper & $\mathrm{t}$ & $\mathrm{df}$ & Sig(2-tailed) \\
\hline & 1 & -2.533 & 5.397 & 1.393 & -5.522 & .455 & -1.818 & 14 & 0.091 \\
\hline The Fifthth Week-Initial & 2 & -2.133 & 9.833 & 2.539 & -7.579 & 3.312 & -.840 & 14 & 0.415 \\
\hline
\end{tabular}

"1" refers to underachievers" extrinsic motivation; "2" refers to underachievers' intrinsic motivation.

Table6 shows that after five-week CL, EFL underachievers' motivation was not improved significantly compared with their initial motivation $(\mathrm{P}>0.05)$.

Interview

The results of the interview show that all achievers and 86 percent of underachievers like CL. Achievers said that they could take a lead and learn others' novel ideas and different perspectives about a certain topic in CL, but eight 
achievers who are group leaders also expressed concern about interpersonal relationships. They are worried CL will kill the friendship when team members have disagreements in group discussions. While underachievers like CL because CL can be fun offering them an environment where they can chat or play with classmates in class. However, they said that they are unwilling to take part in discussion due to their poor English and difficulty in understanding others, and they also feel frustrated because they can't make contribution to the group.

\section{DISCUSSION}

The result of this study shows that both EFL achievers' and underachievers' motivation was enhanced significantly after one-week CL. The finding is in accordance with previous studies (Wang, 2020; Tran, 2019; Kambiss, 1990), which indicates that CL has a significantly positive effect on the motivation of EFL learners. In CL, students' performances are closely linked to team success, which makes students more involved in learning (Slavin, 1990; Daura \& Durand, 2018). Rongrong \& Kusum (2018) think that there is an active interaction between teachers and students in CL, which enhances students' interest in learning (Khodadady et al., 2015; Liu, 2020). Furthermore, most students prefer working together, discussing and sharing information rather than studying alone. CL can offer a cooperative environment and help students develop their language abilities via communication with peers and teachers and imitation of excellent teammates' behaviors. Therefore, students' motivation improves due to active knowledge acquirement (Dewey, 1991; Yager, 2000; Marlow \& Page, 2005).

After three-week CL, the underachievers' motivation declined significantly compared with that of Week One. After five-week CL, underachievers' motivations didn't change significantly compared with those in the pretest, which means that the marginal utility took place in underachievers' motivation during three-week to five-week CL. Deci \& Ryan (1985) think that most people would feel interested in learning something new, but their learning motivation would decline because of incompetence and helplessness. Helplessness refers to helpless behavior and psychological state formed through learning and is very common for underachievers (Seligman, 2005). According to the interview, some underachievers have also mentioned that they were interested in CL at the beginning. However, they feel isolated with the increase of CL time because they think that they didn't make a contribution to group achievements due to their poor performance, while some students just think CL can make them relaxed in class in which they can play or chat with classmates, which means they don't really like CL. Once the teacher requires them to focus on studying, they will lose interest. These may be the reasons for the decline of underachievers' motivation in CL.

After three-week CL, the achievers' extrinsic motivation declined significantly compared with that of Week One. Deci and Ryan (1985) regarded extrinsic motivation as actions carried out to achieve instrumental goals such as earning rewards or avoiding punishments. CL can motivate students' participation in learning and students can get the sense of satisfaction due to praise and recognition from teachers and peers (Panitz, 1999). Achievers are more likely to be praised due to their higher proficiency and more positive involvement. However, going too far is as bad as not going far enough. Too much praise is also a burden for students (Zhao, 2019). According to the interview, some achievers who are group leaders mentioned that being a leader is challenging and stressful because they need to take more responsibility for teamwork and disagreements with group members make them disappointed. These factors may have side effects on achievers' extrinsic motivation.

The achievers' intrinsic motivation has no significant change. The finding is in accordance with Noels' intrinsic motivation theory. He thinks intrinsic motivation is more stable than extrinsic learning motivation, which can carry out learning behaviors without external rewards and pressure (Noels et al., 2000). After seven-week CL, the achievers' motivation increased significantly compared with their motivation in a pretest, indicating there was no marginal utility for achievers' motivation during seven-week CL. This finding can be supported by Rubin (2004). Rubin believes that language achievers generally have some common characteristics: they are good at speculating, dare to express themselves and run a risk despite their limited knowledge of the second language, accordingly achievers can benefit more from CL and the positive effect of CL on achievers' motivation lasts longer.

\section{CONCLUSION}

Research questions put forward in this study are answered as follows: after one-week CL, the EFL achievers' motivation was significantly enhanced; after three-week CL, the achievers' L2 extrinsic motivation declined significantly than that of one-week CL, while their intrinsic motivation has no significant change; after five-week CL, the achievers' motivation tended to be stable; after seven-week CL, the achievers' motivation enhanced significantly compared with that in the pretest, which means that there is no marginal utility of achievers' motivation. After one-week CL, the underachievers' motivation was significantly improved; after three-week CL, the underachievers' motivation decreased significantly than that of one-week CL. However, there is still a significant improvement compared with their motivation in the pretest; after five-week CL, underachievers' motivation didn't have a significant change compared with that of the pretest, which indicates that marginal utility took place.

This study implicates that teachers should make aware of diminishing marginal effect in CL and they need to update teaching methods and instruction timely in order to provide different types of teaching stimulation to students. There should be a wide variety of teaching strategies in class and students should be exposed to different teaching styles. 


\section{Limitations AND SUGgestions For FurTHER STUdy}

First, the researcher reused the same questionnaire five times. Although the order of items is different every time, participants may still have practice effects. Future research may employ more research instruments to explore students' learning motivation. Secondly, teachers of other subjects may also adopt CL in this experimental class, which may have an effect on the results of this study. Thirdly, the sample size is small, so further research involving more participants needs to be conducted in order to explore the change of EFL learners' motivation with the increase of CL time.

\section{ACKNOWLEDGMENTS}

This paper was sponsored by a grant from Social Science Foundation, Hunan Province, China. The project number is 17YBA089.

\section{REFERENCES}

[1] "Above the Margin: Understanding Marginal Utility". Investopedia. Retrieved 2021-11-08. from https://en.jinzhao.wiki/wiki/Marginal_utility.

[2] Adi Purwanto, Mustaji Mustaji, Ketut Prasetyo \& Sukarman.(Eds.).(2018).The Effect of Cooperative Learning Model in Social Science Class. Education Innovation Atlantis Press.

[3] Bai,Y,P. (2009). Cong bian ji xiao yong di jian gui lv kan yu yan shi hua xian xiang [Language fossilization from the law of diminishing marginal Utility]. Ke xue jing ji she hui, 27(02), 46-49.

[4] Daura, F. T. \& Durand, J. C. (2018). What Role Do I Play in My Learning? A Study on the Academic Engagement of Higher-Education Students. European Journal of Education, 1(3), 53-67.

[5] Dewey, J. (Ed.). (1991). Experience and education. Siu Press.

[6] Dörnyei, Z. (1998). Motivation in second and foreign language learning. Language Teaching, 31(3), 117-135.

[7] Dörnyei \& Malderez, A. (1997). Group dynamics and foreign language teaching. System, 25(1), 65-81.

[8] Dong, F.M. (2018).Types of senior high school students' English learning motivation and its influencing factors. Basic Foreign Language Education, (04), 9-17.

[9] Gardner, R. C. (1985). Social Psychology and Second Language Learning: The Role of Attitudes and Motivation. Edward Arnold, (28), 420-421.

[10] Gardner, R. C. (2006). Motivation and attitudes in second language learning. Encyclopedia of Language \& Linguistics, 9(2), 198-217.

[11] Gui, M, Z. (2012). The Study of Diminishing Marginal Utility in Teaching Performance. Education Research, 19 (3), 45-48.

[12] Gülüzar Eymur \& Ömer Geban.(2017).The Collaboration of Cooperative Learning and Conceptual Change: Enhancing the Students' Understanding of Chemical Bonding Concepts. International Journal of Science and Mathematics Education, (15), 853-871.

[13] Harter, S. (1982). The Perceived Competence Scale for Children. Child Development, 18 (3), 38-51.

[14] Hiromori, T. (2006). The effects of educational Intervention on L2 learner's motivational development. JACET Bulletin, 43, $1-14$.

[15] Hua, H, F.(1998). On the motivation and strategies of English learning. Foreign Language Studies, 3 (3) : 44-47.

[16] Kambiss P A.(1990). The Effects of Cooperative Learning on Student Achievement in a Fourth Grade Classroom. academic achievement. 9, 31-41.

[17] Kate Ferguson-Patrick \& Wendy Jolliffe (2018).Cooperative Learning for Intercultural Classrooms. Routledge.

[18] Khodadady, E. , Aryanjam, L., \& Ghazanfari, M. (2015). English language policy and teacher effectiveness at grade three senior high schools. Journal of Language Teaching \& Research, 6(3), 1798-4769.

[19] Jiang, C, Y.(1999) Analysis and countermeasures of the phenomenon of diminishing marginal utility in classroom teaching. Journal of Changzhou Institute of Technology, (02), 92-95.

[20] Johnson, D. W \& Johnson, A. (2003). Students' motivation in co-operative groups: social interdependence theory. New York Press.

[21] Johnson, D. W. (1991). Cooperation in the classroom. Psyccritiques, 36(12), 611-624.

[22] Jr, R. R. , \& Nunez, A. M. . (2020). Motivational factors that influence English as a foreign language learners at quality leadership university, panama city, panama. Journal of Language Teaching and Research, 11(4), 543-550.

[23] Locke, E. A. \&Schattke, K.(2019). Intrinsic and Extrinsic Motivation: Time for Expansion and Clarification. Motivation Science, 5(4), 1-33.

[24] Liu, D.(2006). He zuo xue xi zai shu xue ke tang zhong de an li fen xi [Case study of cooperative learning in situational classroom]. Shи хие jiaо уи хие bao, 15(003), 95-98.

[25] Liu M. (2007). Chinese Students' Motivation to Learn English at the Tertiary Level. Asian Efl Journal, (3):123-150.

[26] Liu, C. (2020). Chinese EFL learners' motivation mediated by the perceived teacher factors - different voices from different levels of education. Journal of Language Teaching and Research, 11(6), 920-930.

[27] Lu, S. J. (2009). Chu zhong ying yu xue kun sheng ying yu xue xi dong ji tang qiu[ On the learning motivation of junior middle school students with English learning difficulties]. Xian dai jiao yu ke хиe, (04), 50-51.

[28] MacIntyre, P.D., Gardner, R.C. (1989). Anxiety and second language learning: Toward a theoretical clarification. Language Learning, 39(2), 251-75.

[29] Marlow, B. A. \& Page, M. L.(2nd ed.). (2005). Creating and sustaining the constructivist classroom, Corwin Press.

[30] Marshall.(2011). Principles of Economics, Vol. 1. The Commercial Press.

[31] Neil Davidson. (2020).Pioneering Perspectives in Cooperative Learning: Theory, Research, and Classroom Practice for Diverse Approaches to CL. Taylor and Francis, 2020-10-13. 
[32] Noels, K. A. (2001). Learning Spanish as a second language: learners' orientations and perceptions of their teacher's communication style. Language Learning, 51, 107-144.

[33] Noels, K. A., Clement, R., \& Pelletier, L. G. (2001). Intrinsic, extrinsic, and integrative orientations of French Canadian learners of English. Canadian Language Modern Language Review, 57(3), 424-444.

[34] Panitz, T. (1999). The motivational benefits of cooperative learning. New Directions for Teaching and Learning, 78(2), $59-67$.

[35] Piaget J.(1980). The principles of Genetic Epistemology. Philosophical Quarterly, 24(94), 87-92.

[36] Polleit, Thorsten. (2011). What Can the Law of Diminishing Marginal Utility Teach Us? Mises Institute.

[37] Roger, T., \& Johnson, D. W. (Eds.).(1994). An overview of cooperative learning. In Thousand, J. S., Villa, R. A., \& Nevin, A. I, Creativity and Collaborative Learning (pp. 1-21). Brookes Press.

[38] Rongrong, Y. \& Kusum, S. (2018). Teacher support, instructional practices, student motivation, and mathematics achievement in high school. The Journal of Educational Research, 111(1), 81-94.

[39] Rubin, Morgan, Galván, \& C.V. (2004). Cooperative Learning, Mathematical Problem Solving. The University Of Texas At Brownsville And Texas Southmost College.

[40] Schunk, D., H \& Pintrich, P, R. (1995). Motivation in education: theory, research, and applications. Routledge Press.

[41] Seligman, Martin E P, Steen. (2005). Positive Psychology Progress. American Psychologist, 60(5), 410-421.

[42] Shamiry, R. , \& Fuad, M. A. . (2020). The role of motivation in second language learning in king khalid university, Saudi Arabia. Journal of Language Teaching and Research, 11(6), 893-903.

[43] Siegel, C. (2005). Implementing a research based model of cooperative learning. The Journal of Educational Research, 98(6), $1-15$.

[44] Slavin, R. E.(2nd ed.). (1990). Cooperative learning: Theory, research, and practice. New Jersey Press.

[45] Slavin, R. E. (1983). An introduction to cooperative learning. New York Press.

[46] Tang, Y,L. (2011). Zhong xue sheng ying yu xue xi dong ji qu xiang wen ti de yan jiu[ A study on the tendency of middle school students' English learning motivation]. Xian dai jiao yu ke xue, (10):27-28.

[47] Tran V D. (2019). Does Cooperative Learning Increase Students' Motivation in Learning?. International Journal of Higher Education, 8(5):12-20..

[48] Vygotsky, L, S. (1977). The development of higher psychological functions. Soviet Review, 18 (3): 38-51.

[49] Wang G .(2020). On the Application of Cooperative Learning in College English Teaching. International Education Studies, 13(6):62-66.

[50] Wang, L,N.(2014). Chu zhong xue shen ying yu xue xi dong ji diao cha yu fen xi[Investigation and analysis of junior high school students' English learning motivation]. Jiao xue yu guan li, (25):45-47.

[51] Wang,T.(2001). He zuo xue xi-yuan li yu ce lue. [Principles and strategies of cooperative learning]. Bei jing xue yuan Press.

[52] Wu, X. Q. (2021). The Impact of Cooperative learning on L2 learning motivation of Senior High School English Achievers and Underachievers. M.A. thesis. Hunan University.

[53] Xiao,C. (2001). Rang xue sheng zai zi zhu he zuo yan jiu xue xi zhong cheng zhang[Let the students work together independently and grow through research and learning]. Bao gao ti gang, (2): 2.

[54] Yager, R. E. (2000). The Constructivist Learning Model. The Science Teacher, 67(1), 44-45.

[55] Yang, F. (2008). Gao zhong ying yu xue kun sheng cheng ying ji tui jing cuo shi chu tang[On the causes and promotion measures of English learning difficulties in Senior High School] Ji xu jiao yu yan jiu, (09):144-147.

[56] Yao, j.(2013). A study on learning motivation of senior high school students with English learning difficulties. M.A. thesis. Suzhou University.

[57] Zhang, S. H. (2011). Application of marginal benefit theory in English vocabulary teaching. Teaching and Management, (27):145-146.

[58] Zhang, X. L. (2017). A Study on English Learning Motivation of High School Students and Poor Students. M.A. thesis. Ludong University.

Xueqing Wu was born in Yunnan Province, China in 1997. She received her M.A degree in English Language Teaching from the School of Foreign Languages of Hunan University in Hunan in 2021. She is now a research assistant at the School of Foreign Languages of Hunan University.

Mingxing Tao was born in Gansu Province, China in 1968. He received his PhD. degree in Foreign Language and Literature from the School of Foreign Languages of Hunan University in Hunan, China in 2019. Now he is an associate professor at School of Foreign Languages of Hunan University. He is a visiting scholar at Yale University. His research interest is English language teaching. 